\title{
A paisagem da cidade histórica e turística: fenomenologia da experiência estética
}

The landscape of the historical and touristic city: phenomenology of the aesthetic experience

El paisaje de la ciudad histórica y turística: fenomenología de la experiencia estética

http://dx.doi.org/10.18472/cvt.16n3.2016.1068

Arley Andriolo < arley@usp.br >

Instituto de Psicologia da Universidade de São Paulo (IP/USP), São Paulo, SP, Brasil.

CRONOLOGIA DO PROCESSO EDITORIAL

Recebimento do artigo: 10 -jul-2015

Aceite: 22-set-2016

FORMATO PARA CITAÇÃO DESTE ARTIGO

ANDRIOLO, A. A paisagem da cidade histórica e turística: fenomenologia da experiência estética. Caderno Virtual de Turismo. Rio de Janeiro, v. 16, n. 3, p. 91-105, dez. 2016.

REALIZAÇÃO

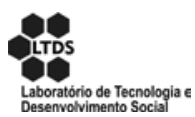

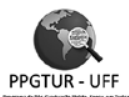

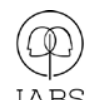

APOIO INSTITUCIONAL

EDIÇÃO

PATROCÍNIO

COPPE

UFR]

EDITORA 


\section{RESUMO}

Esta pesquisa trabalha com a imagem das cidades históricas e turísticas. Mais especificamente, observou-se narrativas de artistas e processos artísticos na visita aos ateliês da cidade de Paraty (RJ). Analisando o trabalho de pintores, notou-se o grande número de paisagens. Na interface entre a psicologia e os estudos do turismo, este artigo pretende desenvolver dois objetivos principais: chamar a atenção para o valor dessas pinturas enquanto objetos da experiência estética e, por meio da abordagem fenomenológica, evidenciar que tais imagens participam da constituição da paisagem e da experiência do lugar.

Palavras-chave: Turismo Cultural. Arte e Turismo. Psicologia e Estética. Comunidades de Artistas.

\section{ABSTRACT}

This research works with the image of the historical and touristic cities. More specifically, one observes narratives of the artists and artistic processes in their studios in Paraty city (Rio de Janeiro, Brazil). Through an analysis of the work of painters, we noticed the great number of landscape paintings. Between the psychology and the tourism studies, this paper attempts to develop two main goals: to draw attention to the value of these paintings as objects of aesthetic experience; and, through a phenomenological approach, to show that these images participate in the formation of the landscape and in the experience of the place.

Keywords: Cultural Tourism. Arts and Tourism. Psychology and Aesthetics. Communities of Artists.

\section{RESUMEN}

Esta investigación trabaja con la imagen de las ciudades históricas y turísticas. Más específicamente, se observó relatos de artistas y procesos artísticos en las visitas a los talleres de la ciudad de Paraty (RJ, Brasil). Al analizar las obras de los pintores, se observó la gran cantidad de paisajes. En la interfaz entre los estudios de psicología y turismo, este artículo tiene la intención de desarrollar dos objetivos principales: llamar la atención sobre el valor de estas pinturas como objetos de la experiencia estética; y, a través del abordaje fenomenológico, demostrar que estés imágenes participan en la formación del paisaje y de la experiencia del lugar.

Palabras claves: Turismo Cultural. Artes y Turismo. Psicología y Estética. Comunidades de Artistas. 


\section{Introdução}

Não obstante a anunciada decadência do gênero paisagístico na pintura, estudos recentes têm focalizado a sua permanência em dois âmbitos distintos da arte contemporânea: nos espaços da arte ambiental, da Land art ou da Earth art; e em referências à "nova paisagem”, a qual, porém, está muito distante da representação da natureza. Como notou, Frederico Morais (1995, p. 10):

passado o período áureo da abstração, a figura retorna, mas a "nova paisagem" nada mais tem a ver com a observação da natureza: no máximo ela evoca sentimentos ou emoções. O pintor não se coloca mais devant la nature, mas devant la peinture, ela mesma. Suas paisagens são puras invenções. Conceitos.

Ao pesquisador que não se restrinja às classificações do campo artístico, projetando o olhar para um campo mais expandido do que aquele circunscrito pelo discurso e pelas relações de poder, encontrará uma produção pictórica instigante nas cidades turísticas. Essa pintura é descartada pela crítica especializada, por representar uma sobrevivência tardia de práticas superadas historicamente, ou meramente designada de "arte turística"; objeto destinado ao consumo no mercado do turismo.

Quando se percorre cidades turísticas como Ouro Preto, Paraty ou Olinda tem-se diante do olhar diversas manifestações artísticas, de esculturas a bordados, de mosaicos a poemas e performances. Em algumas delas, o grande número de pinturas salta aos olhos e, quando nos detemos sobre essas imagens, é notável a grande quantidade de paisagens. Na França, a paisagem pictórica sobreviveu na costa da Normandia, em Barbizon e Auvers sur Oise, cidades turísticas que se desenvolveram em grande medida com a atividade de artistas viajantes ou residentes.

Apesar do interesse interdisciplinar da pesquisa em turismo, particularmente em relação à psicologia (e.g. MANNEL; ISO-AHOLA, 1987; POTTER; COSHALL, 1988; ROSS, 2001; PEARCE; STRIGER, 2001; PEARCE, 2005), os estudos sobre as artes e a experiência estética permanecem raros. Muitos vêm sendo realizados por outras disciplinas, notadamente a antropologia, sem a contribuição da perspectiva fornecida pela psicologia (e.g. COHEN, 1993; GRABURN, 1994).

Este trabalho integra o conjunto de investigações sobre comunidades nas quais a atividade artística é relevante, notadamente em cidades turísticas de valor artístico, tais como Ouro Preto, Olinda e Paraty, entre outras. Neste artigo serão apresentados resultados desse projeto em três partes. Primeiro, procede-se à conceituação de paisagem e experiência estética conforme a abordagem fenomenológica. Em seguida, são sintetizadas as informações sobre a história das comunidades de artistas surgidas na confluência com o desenvolvimento do turismo no Brasil. Para concluir, os dados específicos da pesquisa de campo em Paraty conduzem à discussão acerca dos significados da paisagem da "cidade histórica". Neste trabalho, utiliza-se o termo "cidade histórica" de modo genérico para referir ao conjunto de cidades pesquisadas, tal como são expressas em narrativas e discursos, apesar da sua imprecisão conceitual ante os núcleos urbanos de reconhecido valor patrimonial.

$\mathrm{Na}$ interface entre a psicologia da experiência estética e os estudos do turismo, este artigo pretende desenvolver algumas reflexões acerca do trabalho de artistas de cidades históricas e turísticas, seguindo dois objetivos principais: (1) chamar a atenção para o valor dessas manifestações artísticas enquanto objetos da experiência estética, as quais, embora pertinentes ao mercado turístico, não são unicamente destinadas ao "olhar do turista"; (2) por meio do conceito fenomenológico de engajamento, evidenciar que as imagens de arte participam da constituição da paisagem e da experiência desses lugares. 


\section{Paisagem, fenomenologia e método}

De modo sintético, a designação de "paisagem" refere a um lugar e aparece em muitas línguas ocidentais, conforme Roger (2000, p. 33): landscape, landschaft, paisaje, paesaggio, paysage, paisagem. Na forma de land ou pays, circunscreve-se uma região conhecida daquele que percebe - na raiz latina, pagus refere-se a povoado. A designação aparece na forma de landschap, em holandês, na segunda metade do século XV. Conforme Schama (1996, p. 20), a palavra landscape

entrou na língua inglesa junto com herring (arenque) e bleached linen (linho alvejado), no final do século XVI, procedente da Holanda. E landschap, como sua raiz germânica, Landschaft, significava tanto uma unidade de ocupação humana - uma jurisdição, na verdade - quanto qualquer coisa que pudesse ser o aprazível objeto de uma pintura.

Segundo esse autor, os italianos trataram de modo equivalente como parerga, "o ambiente idílico e pastoril de riachos e colinas cobertas de dourados trigais".

A paisagem constituiu-se na pintura em torno de temas provenientes da natureza -montanhas, planícies, florestas, cursos de água, lagos, praias -, cenas designadas pitorescas. São elementos naturais em relação à experiência cultural, sobretudo na referência às paisagens "nacionais" dos pintores, em marinas e montanhas. Muito antes, a série de referências iniciara-se com Petrarca (1336) a subir ao Monte Ventoux. Depois de 1850, as montanhas cederam lugar aos campos e arredores de Paris. Trata-se de uma passagem entre a categoria de pitoresco e a de nacional, quando relevam as terras cultivadas e vilarejos com torres de sinos. Em contraposição, falava-se em paisagens urbanas e industriais, nas quais o belo não seria a categoria da experiência estética (LAJARTE, 1995, p. 37).

Desde o século XVIII, todo o interesse para os aspectos sensíveis da natureza, porém, estava permeado por uma concepção dualista de natureza e uma percepção baseada no "olhar desinteressado" em uma nova teoria estética. Como diria o filósofo Arnold Berleant (1992), a ideia de natureza formou-se entre a proposição de Locke, na qual a natureza é "externa" ao ser humano, e a de Spinoza, em uma integração orgânica "interior". No domínio das belas artes, instituiu-se uma teoria da estética baseada no "desinteresse" e na "autonomia da pintura", quando a arte tornou-se um modelo para a apreciação da natureza (BERLEANT, 1995).

Estudos sobre paisagens têm recentemente circunscrito pesquisas elaboradas no cruzamento de três referências: o simbólico, o iconográfico e o ambiente geográfico. Nessa linha, por exemplo, foi organizado o volume de Cosgrove e Daniels (2000), especialmente enfocando as relações entre a representação simbólica e os usos de "ambientes históricos". Os organizadores afirmam que a paisagem é uma imagem cultural, o meio de representar ou estruturar simbolicamente os lugares. De tal modo que a pintura, ou outros objetos icônicos, é parte importante da relação entre o observador e o ambiente.

A natureza, as montanhas, as praias, as cidades históricas, as igrejas e os casarios são objetos culturais, não apenas coisas físicas: são resultantes de processos sociais que envolvem a organização do mundo percebido. A paisagem constitui-se através da experiência, não como um objeto, mas como uma totalidade, como notaram os autores da fenomenologia (BERLEANT, 1992; BOCKEMÜHL; SOMBART, 1992; TILLEY, 1994); um fenômeno integral do qual somos parte.

Nas palavras de Ulpiano Bezerra de Meneses (2002), a paisagem forma-se como uma experiência cultural, é algo material que se dá à percepção, mas não como um dado a priori, dispõe-se em uma relação entre observador e objeto. Portanto, não se deve pensar a percepção de modo realista, supondo uma materialidade e objetividade morfológica da paisagem, tampouco de maneira idealista, como projeção do observador. Por essa razão, pode-se falar que a paisagem, a montanha, o casario, a cidade, têm história, pois constituem-se através da experiência sensória, a qual poderá elevar-se ao plano da estética (p. 32). 
Em diversos estudos sobre a experiência da viagem, desde as referências históricas procedentes do mundo dos viajantes até as atividades turísticas, a experiência estética aparece de modo subliminar. Notadamente, entre os tópicos fundamentais desse tipo de experiência estão: o espaço, o tempo, o outro, o eu (ou em relação a si) (e.g. ADLER, 1989; AMIROU, 1995; RAUCH, 2002). Relembrando os escritos de Johann Wolfgang von Goethe, em sua viagem à Itália, o deslocamento no espaço e no tempo possibilitou-lhe a elevação da percepção em direção ao outro, notável entre habitantes e artistas, por meio da paisagem. Para Goethe (1999), embora o olho fosse um órgão natural da percepção, era formado pela experiência e também poderia ser desenvolvido. O procedimento que conduzia o olhar era mediado pela presença constante de obras de arte e pelo convívio com outros artistas.

Nesse escritor, os atos de pesquisar, escrever e desenhar estavam unidos em uma só linguagem (ANDRIOLO, 2011). A experiência da viagem revelou-lhe o sentido estético: "a visão da paisagem magnífica à minha volta não desaloja em mim o senso poético; bem ao contrário, acompanhada do movimento e do ar livre, ela o suscita com maior rapidez." (GOETHE, 1999, p. 26). Assim, a paisagem não é apenas um objeto exterior, mas a totalidade da experiência que emerge dos processos e das mediações entre a percepção, a emoção e a cognição em relação com o mundo sensível. A visão da paisagem suscita a experiência estética.

Para o conhecimento por meio da experiência, recorre-se à fenomenologia. Nesse âmbito, situa-se uma abordagem fenomenológica empírica e social, em atenção às narrativas, imagens e descrições de experiências. De modo geral, seguem-se os procedimentos de uma fenomenologia ligada aos processos sociais, em estreita colaboração com a psicologia em seus aspectos ligados à vida cotidiana e às formas políticas (SCHUTZ; LUCKMANN, 1974). Conforme essa abordagem, as formas e significados são apreendidos na experiência, tal como aparecem na vida cotidiana de sujeitos, em padrões, temas e categorias, identificados pelo pesquisador (LANGDRIDGE, 2008).

De modo específico, trata-se de descrever a experiência tal como aparece aos artistas, espectadores, entre outros agentes do campo estético. Na filosofia fenomenológica, a concepção de estética tem variado muito desde a formulação original em Moritz Geiger (1958), seja em Dufrenne (1967/2004) ou em Merleau-Ponty (1964), entre outros. Na pesquisa empírica interessa, sobretudo, a experiência recolhida pelo pesquisador, da qual emergem categorias próprias. Ao considerar um campo estético específico, na acepção de Arnold Berleant (1970), releva-se tanto os agentes participantes do campo - o artista, o espectador, o marchand, etc. - quanto os elementos constitutivos do espaço e tempo do acontecimento do objeto ou processo artístico. Desse modo, o próprio ambiente é requisitado, assim como a cultura e a natureza.

Nesta pesquisa, foi circunscrito como fenômeno a atividade dos artistas nas cidades históricas e turísticas. As cidades de Ouro Preto e Paraty têm sido observadas, e suas características descritas em relação à história do desenvolvimento do turismo (ANDRIOLO, 2008; 2014). Neste artigo, serão apresentados os resultados específicos da investigação realizada em Paraty onde foram coletadas narrativas de artistas e observados os processos e objetos artísticos em visita aos ateliês. Na pesquisa de campo, registrou-se a diversidade de grupos sociais dedicados à atividade artística, ocupando regiões significativas do espaço urbano. São índios da etnia guarani, caiçaras, quilombolas, pintores acadêmicos, aquarelistas, representantes da arte experimental, entre outros, resultando em objetos muito variados. A partir da observação direta, procedeu-se à identificação nominal de artistas e à descrição das qualidades de sua produção.

Ao final, foram 32 artistas cadastrados, dos cerca de 40 que viviam na cidade. Vinte e cinto trabalhavam com artes relacionadas à pintura, incluindo desenhistas, aquarelistas e autores de técnicas mistas, entre as quais painéis com massa de cimento, gesso ou papel machê, cujo resultado são superfícies pictóricas em relevo. O grande número de pintores, particularmente de paisagens, suscitou a elaboração deste artigo. Os pintores foram convidados para entrevistas e tornaram-se verdadeiros colaboradores da pesquisa, forne- 
cendo informações preciosas sobre as relações entre a arte e a paisagem em Paraty. Foram realizadas nove entrevistas abertas e registros fotográficos nos ateliês.

A coleta de material nos ateliês possibilitou a integração de categorias surgidas das narrativas dos artistas com aquelas provenientes de fontes bibliográficas e documentais da pesquisa. A orientação fenomenológica em psicologia social procura descrever a experiência da percepção, particularmente, conforme categorias identificadas nas narrativas dos sujeitos, reconhecidas como classificações de estímulos visuais específicos no espaço social e no tempo histórico. Tais categorias expressam em palavras a experiência estética desde termos convencionais como "sublime", "pitoresco", "exótico", até enunciados próprios do campo estético de Paraty.

No próximo item, uma breve história da pintura nas cidades históricas e turísticas do Brasil fornece um quadro introdutório, a partir do qual o valor artístico dessa produção mostra-se com maior clareza e os resultados da pesquisa em Paraty tornam-se mais compreensíveis. Na sequência, os dados específicos de Paraty permitem articular a imagem de arte com a percepção da paisagem, preparando a conclusão por meio da compreensão fenomenológica da experiência estética.

\section{Imagem pictórica das “cidades históricas” brasileiras}

De modo esquemático, poder-se-ia dividir a história do turismo no Brasil em quatro momentos articulados: (1) Do século XIX até a primeira década do século XX: circulação de viajantes estrangeiros pelo Brasil com fins científicos, início de viagens mais regulares de filhos das elites brasileiras para estudos no exterior; (2) Primeira metade do século XX: um "turismo eventual", sem organização e regularidade nos pacotes, principalmente voltado para a venda de passagens de navios para o exterior, com a intensificação da prática das elites em enviar seus filhos para a Europa; viagens nacionais principalmente via marítima; (3) Entre os anos de 1950 e 1970, "organização empresarial do turismo", com os primeiros pacotes regulares e incremento dos produtos, com a inclusão, ainda tímida, do transporte aéreo - a criação da Embratur data de 1966; (4) Dos anos 1980 aos nossos dias difundem-se as viagens rodoviárias e aéreas, notam-se a ampliação da oferta hoteleira, a seleção rígida de pontos de interesse e a padronização do consumo turístico.

O interesse pelos atrativos organizados em torno de objetos artísticos aparece nas décadas de 1950 e 1960, sobretudo, com o reconhecimento da "arte barroca" (ANDRIOLO, 2010). A procura de pacotes turísticos que tenham a arte, ou mesmo o patrimônio histórico, como atrativo primário permanece restrita no Brasil, a despeito de seu crescimento nas últimas décadas, com o incremento dos espetáculos teatrais e musicais (PIRES, 2001). A arte aparece, em grande parte, como atrativo secundário, completando a estadia do grupo mobilizado por outros motivos.

No caso das chamadas "cidades históricas", arquitetura e artes visuais são atrativos importantes em Ouro Preto, Salvador ou Olinda, mas sabe-se da procura primeira por um ambiente distinto daquele da vida cotidiana, que seja identificado com certo bucolismo. Em menor número, encontramos os leigos interessados em ampliar seus conhecimentos sobre a história e a arte do país, ao mesmo tempo em que desfrutam de uma viagem de descanso, ou de grupos escolares. Por fim, aparece o reduzido público especializado (artistas, historiadores, arquitetos, etc.) que viaja em excursões de escolas e universidades, ou individualmente, com a finalidade primeira de conhecer aspectos culturais de seu interesse.

Convém lembrar que a articulação entre o turismo e a imagem de arte no Brasil se estabeleceu entre o modernismo e a formação da categoria de "barroco". Como demonstrou Andriolo (2010), as viagens de intelectuais paulistas em busca de referências estéticas para a uma história da arte brasileira conduziu-os a 
Minas Gerais, onde as edificações, esculturas e pinturas do século XVIII foram identificadas como origem de nossa arte. São exemplares os escritos de Mário de Andrade e Lourival Gomes Machado. Nesses dois autores, e entre tantos outros nas duas gerações do modernismo, o barroco mineiro emerge como objeto estético e atrativo turístico.

Na formação do campo turístico, as imagens produzidas com a temática das "cidades históricas" contribuíram para a ampliação da área de recepção definida pelas publicações literárias nos grandes centros urbanos da metade do século XX. Por sua vez, os poderes públicos locais, sobretudo nas antigas cidades de exploração aurífera em Minas Gerais, apropriaram-se da função social das imagens de arte.

Durand (1989) notara as inter-relações entre as práticas artísticas, o turismo e a defesa do patrimônio histórico. Em abordagem sociológica, examinou o quanto a valorização da cultura material das cidades remanescentes do século XVIII e a proposição de uma arte nacional na categoria de "barroco" fomentou o surgimento de um circuito de viagens e estimulou o comércio de obras de arte antigas e contemporâneas, notadamente a pintura. Diversos aspectos dessas cidades converteram-se em temas inesgotáveis em pinturas. Ouro Preto é o exemplo mais famoso do Brasil, a primeira cidade a estabelecer-se na articulação entre o passado artístico nacional e a prática artística contemporânea. Ali, o pintor Alberto da Veiga Guignard foi o nome de destaque (ANDRIOLO, 2008).

Embora as ligações entre essas pinturas e o desenvolvimento do turismo sejam notáveis, tratá-las unicamente como objetos destinados ao mercado turístico seria um equívoco e resultaria em incompreensão acerca do lugar das imagens na sociedade brasileira. Além da relação com o olhar do turista, os pintores propõem olhares sobre a paisagem. Carlos Bracher, por exemplo, vive em Ouro Preto desde 1971 e diversas pinturas suas transformam a cidade em imagens. Carlos Scliar morou na mesma cidade, não se limitou à temática local e tampouco destinou suas obras ao consumo do turismo. Ambos encontraram na cidade um ambiente importante de trabalho e elementos para suas composições.

Outros artistas mantêm a paisagem e o ambiente como tema, a exemplo de Fernando Lucchesi, com seu ateliê em Ouro Preto:

resgatando o imaginário popular dos objetos rituais da tradição mineira encontrado nos oratórios, candelabros, vitrais, flores, armários, mesas e baús, Lucchesi constrói um outro fragmento da paisagem mineira, recriando, com refinamento artesanal e vibração cromática, as histórias cotidianas do barroco, da colônia... (RIBEIRO, 2000, p. 303)

Poder-se-á esboçar conexões entre os artistas circulando pelas diversas cidades históricas e turísticas brasileiras, criando um imaginário artístico compartilhado. A pintora Djanira da Motta e Silva trabalhou sobre paisagens tanto em Paraty quanto em Ouro Preto. Na primeira, chegou a morar na década de 1950, quando adquiriu um sítio com o marido. Mário Barata (1985, p. 20) considerou que a pintora "encantou-se com o bucolismo e os horizontes de Paraty". Em sua ampla produção, a experiência da arte e da arquitetura coloniais resultará em estudos de iconografia católica, seja na forma de azulejos, seja em pinturas e desenhos de figuras sacras.

A pintura de paisagens pode ser vista nas telas de Omar Pellegatta ao visitar cidades como Ouro Preto, Tiradentes, Mariana, São João del-Rei, Sabará e Paraty. Nesta última localidade, realizou trabalhos focalizando aspectos urbanos, sobretudo, destacando arquitetura religiosa e casario. As cores representam um componente importante da composição, especialmente em janelas e portas, amarelas, verdes, azuis, mas também nos detalhes desgastados dos edifícios, que em tons esverdeados ou amarronzados reforçam uma categoria temporal.

Outro exemplo, Arnaldo Navajas Filho (nascido em São Paulo) iniciou sua carreira com trabalhos no Parque do Ibirapuera, depois pintou representações das cidades de Embu e Santana de Parnaíba (SP). Navajas Filho frequentou as aulas de Ado Malagoli, no III Festival de Inverno em Ouro Preto, em 1974, 
produziu uma série de óleos e aquarelas e realizou exposições em Ouro Preto e Belo Horizonte dedicadas ao "barroco".

Márcio Franco (nascido em Lagoa Santa, MG) visitou tanto os ateliês quanto os festivais de Ouro Preto, durante a década de 1970, nos quais pôde desenvolver sua técnica. Depois, participou de atividades na escola de artes do Parque Lage, no Rio de Janeiro, e dos cursos da UFMG, para então fixar-se em Paraty, no ano de 1982. Sua linguagem elabora temas tropicais, da fauna e da flora, aplicados a grandes formatos. Nas estadas em Ouro Preto, Márcio Franco conheceu a técnica de Carlos Scliar. Face aos vínculos com as cidades históricas de Minas, poder-se-ia citar também Helen Navajas (natural de São Paulo), que viveu em Ouro Preto antes de mudar-se para Paraty.

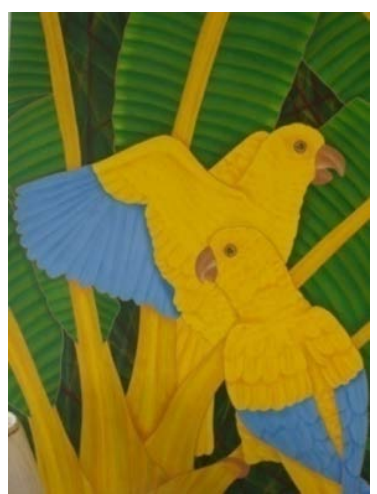

\author{
Márcio Franco, Papagaios, acrílico sobre tela, Paraty, 2008. Fotografia do \\ autor, 2009.
}

Nos guias escritos por Gilberto Freyre, dedicados às cidades do Recife e Olinda, nos anos de 1934 e 1939, respectivamente, encontra-se um tópico voltado a pintores e fotógrafos. "Recife é a cidade dos pintores", afirma de início, e continua: "Talvez por causa de sua luz. Talvez a sua luz seja um estímulo à pintura mais do que a qualquer outra arte." (FREYRE, 1934/1968, p. 56). Entre eles, Teles Júnior “foi

paisagista que se deliciou em pintar águas recifenses" (p. 57). Cita também Fédora do Rego Monteiro Fernandes, Mário Nunes, propriamente um paisagista, e Lula Cardoso Ayres, cujo ateliê em Boa Viagem lhe desvela a paisagem marítima. Entre outros, foram esses mesmos pintores os que se dedicaram às paisagens de Olinda em meados do século XX.

Por fim, a cidade de Paraty ingressou nesse processo de modo significativo, geograficamente estabelecida entre Rio de Janeiro e São Paulo, atualmente situada no roteiro turístico da "Estrada Real". Na década de 1970, a pintura de paisagens que articula a imagem pitoresca ao sentido documental da arquitetura pode ser vista nas telas de Omar Pellegatta, Hiroshi Murakami e Paulo Gomes. Djanira é considerada a precursora do espaço plástico "ingênuo", hoje praticado por Júlio Paraty e outros paratyenses, tal como João José da Silva e Lúcio Cruzz, bem como Themilton Tavares, radicado desde 1975. O tema do Divino aparece em muitos desses trabalhos, desenvolvendo elementos das festas e tradições populares, embora esse espaço visual varie muito entre os artistas, na técnica, na forma e no conteúdo dos trabalhos (ANDRIOLO, 2015).

As manifestações plásticas das últimas duas décadas em Paraty abrem-se para novas significações no espaço visual, ao mesmo tempo em que perdura um núcleo imagético tradicional. Durante a década de 1990, ocorreu grande afluxo de artistas, congregando desde paisagistas e abstracionistas até práticas propriamente contemporâneas em composições e experimentalismos, a exemplo de Sérgio Atilano e Fernando Fernandes. Conforme concluiu-se naquele estudo, as imagens continuam a movimentar-se entre dois polos: novas experiências visuais e representações de paisagem em formas diversas.

\title{
Que dizem os pintores sobre a paisagem?
}

Mais detalhes acerca da interpretação das imagens de arte produzidas em Paraty são encontrados no artigo acima citado, quando demonstrou-se a atualidade do conceito de mimesis para a compreensão 
da pintura (ANDRIOLO, 2015). Trata-se de um jogo mimético não porque se detém no modelo da imitação, mas devido à combinação entre semelhança e diferença através da paisagem. Neste momento, interessam as narrativas dos pintores e o que nos revelam de suas experiências em relação à paisagem, por meio da atividade pictórica. Entre os nove pintores entrevistados, apenas dois dedicam-se à pintura abstrata. Todos os outros trabalham sobre temas figurativos, notadamente sobre elementos provenientes do ambiente local de Paraty: o casario, o mar e a serra. Dos não figurativos, um deles foi contundente em afirmar que sua experimentação não é pura composição de formas - ao contrário do outro abstracionista -, mas uma revisão das formas sensíveis do espaço urbano e natural local. Desse modo, a maioria dos pintores entrevistados dispõe-se a uma relação com o mundo paratyense cujo resultado é a sobrevivência do espaço visual da paisagem, sobre o qual elaboraram os comentários seguintes.

Durante uma estada de três meses em Paraty, Márcio Franco teve sua atenção atraída pela cor verde: "é uma região verde, você tem verde em volta, uma variedade absurda de verde". No meio da folhagem, via brotar outra cor, o vermelho, o laranja, o amarelo, diversas florações e animais, sobretudo pássaros. O fundo verde de seus quadros deriva dessa visão, verde sobre o qual organiza as formas em cores bem demarcadas. Diferentemente do gênero paisagístico clássico, aumenta a lente, aproxima-se dos detalhes da floresta e os transforma em imagem na grande escala da pintura sobre tela. Trata do assunto apontando um de seus trabalhos onde figuram helicônias. Reforça também a observação das bananeiras, nas passagens do verde em amarelo e da inflorescência rósea. Conforme afirmou, o ponto colorido é o ponto de partida.

Marília Inke é amante das caminhadas na natureza. Descobriu a natureza de Paraty aos poucos. Comenta: "Eu sempre tive essa vontade de conseguir retratar a natureza com meus olhos, da minha forma de ver, que não é real, a ideia é ter uma característica própria para retratar a natureza." Mas os elementos históricos também chamam sua atenção, atraem muitos turistas e artistas para o lugar, os artistas conversam, trocam ideias, o espaço do ateliê aproxima o espectador do trabalho do pintor. Os diálogos giram em torno de categorias específicas da percepção da cidade: "vista bonita"; "cidade inspiradora"; "um olhar para a arte"... São categorias compartilhadas na experiência de artistas, no olhar do turista e no imaginário da cidade. Observe-se a situação da Igreja de Santa Rita, a beira-mar com as montanhas ao fundo, uma vista privilegiada e compartilhada.

Enquanto Marília dedica-se à pintura em tinta acrílica sobre papel ou folha de bananeira, seu companheiro Ricardo Inke é aquarelista. Ele prefere falar dos efeitos de luz sobre as coisas que propriamente de paisagens. Como os impressionistas, explora as variações da luminosidade durante os dias, horários e épocas do ano. Nas palavras do artista, a relação entre luz e sombra é mais importante que a beleza plástica do lugar em si, desta rua ou daquela casa específica. Essa concepção resulta do aprendizado com outros aquarelistas, notadamente, segundo conta, do convívio com os europeus. Em suma, uma paisagem "sem graça", "singela", pode ser explorada nos efeitos de luz e sombra, destarte, não se pinta as "paisagens bonitas", as coisas óbvias. O belo é extraído da imagem pelos efeitos de luz.

No trabalho de Ricardo Inke, a mimesis opera com o recurso ao objeto natural ou artificial, em uma recusa parcial ao objeto, reconhecido no jogo de cores que nunca abandona a figuração. Pondera sobre as técnicas: "No desenho a bico-de-pena, talvez aí sim, a busca do belo como vista bonita seja mais importante." De outro lado, o esforço pela técnica artística não o faz abandonar as palavras acerca da expressão: "Na pintura, a ideia não é reproduzir o que a gente está vendo ali no momento, mas é passar para a pintura a emoção ou o sentimento que aquela paisagem causa e que você queira passar isso adiante". Diferentemente do desenho e da fotografia, a pintura toma a paisagem como referência sem a copiar, "a partir daí viaja-se". 


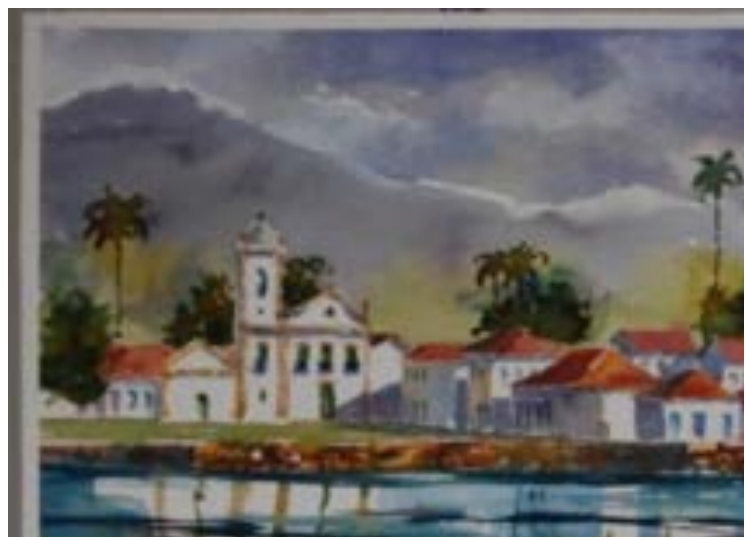

Ricardo Inke, Vista da Igreja de Santa Rita, aquarela, Paraty, 2011. Fotografia Ricardo Inke.

Pintor esmerado na técnica clássica acadêmica, André Meurer desenvolve em toda sua narrativa uma concepção acerca da relação entre o artista e seus objetos, em termos como "dom" e "inspiração"; o gênero paisagístico está sempre em pauta. Afirma:

A paisagem, ela é o meu eu. É o meu interior. Tudo o que você queira se referir em relação à paisagem... porque a paisagem eu posso definir ela como vários caminhos. Eu posso definir ela como um prédio, uma árvore, uma cachoeira, um mar, um bosque, uma vegetação, um deserto. Até um deserto tem a sua beleza. Uma paisagem, ela está dentro de mim. A paisagem sou eu.

Atualizada no pensamento contemporâneo do artista, a concepção clássica infiltra na percepção toda a sensibilidade do observador. Pois se a paisagem é o artista, ela deve ser como ele: "A paisagem, na verdade, é o meu eu. Se eu não sou feliz comigo mesmo, eu jamais consigo ver aquela paisagem, por mais mórbida que seja, bonita. Isso é o que eu vejo, na paisagem. É o meu interior, é o meu eu”. O jogo da mimesis está subvertido, entre o jogo de projeções do eu sobre o mundo em comum, sem o abandono das categorias clássicas, da ideia do belo, mescla a imagem do artista e a noção de expressão.

Outro exemplo de grande habilidade técnica é José Andreas, aquarelista, originalmente formado em Desenho Industrial e também músico. Para o artista, o desenhista desenvolve uma forma de olhar diferente de outras pessoas porque percebe o mundo como desenho. Essa afirmação parece conter tanto o desdobramento de uma concepção clássica quanto uma visão política do trabalho do pintor. "Então, digamos assim, uma paisagem que tenha determinada árvore, um pedacinho de mar, um barco. Eu olho aquilo e já vejo traduzido em desenho; uma pessoa que está passando ali vê uma árvore, um mar, um barco." Embora trabalhando sobre figurações do espaço paratyense, não está circunscrito à concepção clássica. Recorda-se do grande significado que a escola de desenho industrial cumpriu em sua vida, pela importância dessa formação nos anos 1970, instigando o debate cultural e visual. Houve para ele um aprendizado visual que o possibilita hoje compartilhar formas de perceber com outros artistas. Assim, não tratava da qualidade da pintura ou do resultado final do trabalho, mas de um "olhar aprofundado". Esse seria o seu "ingrediente" para fazer algo "diferenciado", depois vem a competência.

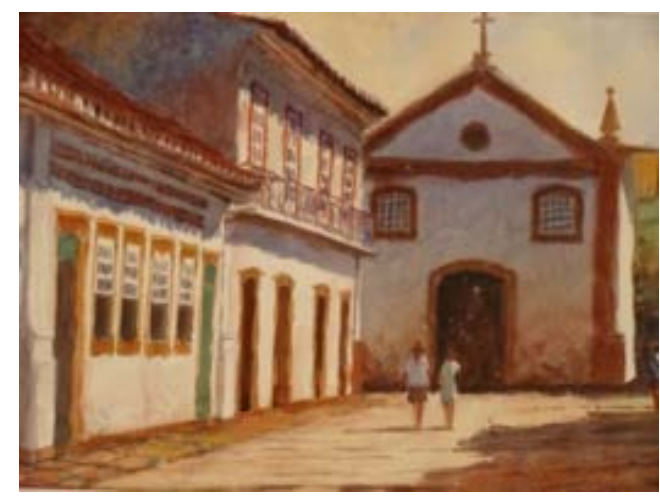

José Andreas, Igreja do Rosário, Paraty, aquarela, 2009. Fotografia do autor, 2009.

Único nativo de Paraty, entre os artistas com os quais o autor conversou, Júlio Paraty sempre trabalha sobre o tema da paisagem, no modelo ingênuo que o caracteriza. Exclama: "Paisagem porque é uma cidade linda!". Explora o universo das festas populares, a arquitetura, dispõe o casario em volumes e sempre apresenta uma igreja. Refere-se a um de seus guaches, inti- 
tulado Nossa Senhora das Dores: "Não tem uma figura, só tem a igreja e o pátio na frente". A ausência de personagens reforçaria o valor do monumento e seu aspecto paisagístico, depois, o pintor lembra-se que retratou ali também um menino empinando pipa. Durante a conversa, está sempre a comparar os lugares como eram há 30 anos e sua situação atual. Casas, flores, a imagem da pintura o ajudam a relembrar e a converter os lugares em traços ingênuos.

\section{A fenomenologia da experiência estética}

Há duas concepções de paisagem expressas nas narrativas dos pintores: uma vincula o interior do artista ao seu projeto de criação, os elementos do mundo exterior são subterfúgios, mais ou menos necessários, para a realização de si e do trabalho manual da pintura; outra se ancora sobre as qualidades externas do meio ambiente natural e construído, a serem transformadas em imagem pictórica, para a apreciação do espectador. Essas duas posições alternam-se nos pintores entrevistados. As palavras de Deborah Col Costa são exemplares dessas concepções e suas ambiguidades: "A alma se torna paisagem na reconstrução pictórica do mundo" (FESTIVAL DOS ARTISTAS DE PARATY, 2006, p. 20).

Mesmo em artistas voltados à experimentação, as trocas com o ambiente são sensíveis. Sérgio Atilano é exemplar. Em seu trabalho, o jogo da mimesis é levado para fora da tela, em dois procedimentos conjugados: primeiro, na dimensão material; segundo, na forma. No primeiro procedimento, recolhe elementos da natureza, gravetos, sementes, entre outros, os quais são manipulados, reunidos, dispostos em superfícies, às vezes pintados. No segundo, o arranjo das formas entre a matéria natural e o trato artificial pode referir a ruas, montanhas, logradouros, etc. Atilano, como outros artistas estabelecidos na cidade, tem uma forte ligação com a história e os processos políticos, econômicos e ambientais da localidade. Em suas caminhadas por Paraty, recolheu caquinhos de cerâmica a beira do mar, às vezes os pintava, outras deixava na cor natural: "A aplicação disso é uma estória das pedras. A cidade, para mim, é dessa forma, ela está presente, às vezes no jeito de montar o trabalho". Embora distante da fórmula imitativa, a referência ao lugar aparece na composição das formas e cores, articulada não à observação direta, mas à experiência do pensamento, da memória e da imaginação.

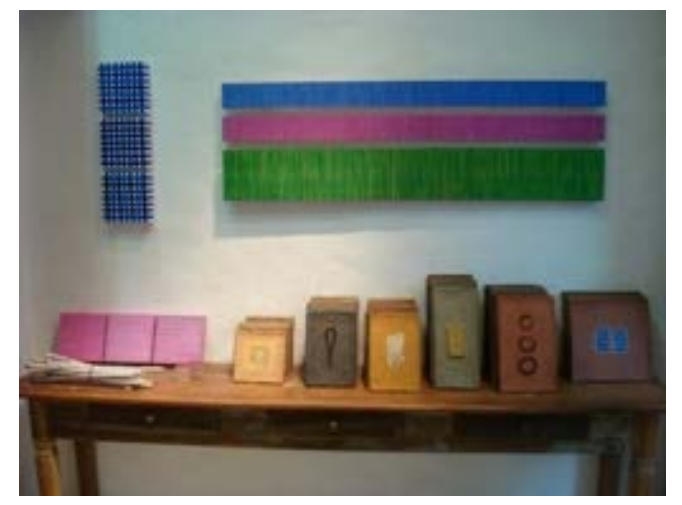

\section{Sérgio Atilano, Ateliê Bananal, Paraty, 2009. Fotografia do autor.}

As ambiguidades que emergem das narrativas discernem o dualismo entre o eu e a paisagem, dentro e fora, entre sujeito e objeto da relação, as quais podem ser compreendidas pelo conceito de engajamento, conforme a abordagem fenomenológica. Afirmou Arnold Berleant (1995, p. 238): "Engajamento, então, é a direção na qual a estética da natureza nos conduz."

Continuando: "Uma estética do engajamento engloba ambas, arte e natureza, e é o que esperamos que qualquer boa explicação deva fazer - resolver mais problemas que criá-los." (p. 241).

A formulação de Berleant acerca do engajamento foi originalmente redigida em 1970, em seu primeiro livro dedicado à fenomenologia da experiência estética. Na abordagem de Berleant (1970/2000), o conceito de engajamento resulta de uma revisão crítica da teoria da "arte desinteressada", aquela que separa sujeito e objeto, além de criar categorias de distinção social e a segregação do artista e do espectador. 
Particularmente, a partir das transformações artísticas da década de 1960, em happenings e performances, afirmou-se o caráter participativo do espectador. Desde então, engajamento tornou-se um conceito-chave para refletir sobre as relações entre arte e natureza e a estética ambiental.

O conceito de engajamento foi desenvolvido a partir da fenomenologia de Maurice Merleau-Ponty e da retomada de Husserl, nas interfaces com a psicologia social de Kurt Lewin e a concepção de experiência estética em John Dewey. Arnold Berleant (2010, p. 19) conduziu o estudo do campo artístico para o espaço ambiental e social, atingindo o domínio do que designou estética política.

Portanto, trata-se de rever uma concepção corrente de estética, derivada do século XIX, na qual o estético é uma exceção, experiência que "transcende" a vida cotidiana. O estético e o artístico estão próximos no plano do conhecimento, mas tratam de problemas distintos nas ciências humanas. O primeiro diz respeito aos sentidos e à percepção. O segundo trata da delimitação de um campo social que classifica $\mathrm{e}$ hierarquiza os objetos.

Veja-se a definição original do termo estética, em sua etimologia, sobretudo, porque atualmente os usos vulgares são muito diversos. Na metade do século XVIII, Alexander Gottlieb Baumgarten (1750) forneceu a definição de estética como a ciência do conhecimento sensório. Devido à vinculação da categoria do belo, foi aproximada do debate das artes durante o século XIX (em uma concepção de arte acadêmica). Porém, tratava-se de uma ciência e não uma oposição a esta, destinada a explorar a experiência sensória. Baumgarten retomou o significado dos gregos, literalmente "percepção pelos sentidos" (aisthesis) (BERLEANT, 2010, p. 26 e 34). Assim, a dimensão estética é um domínio central da experiência.

Desse ponto de vista, a estética não é uma verdade universal e imutável, mas uma possibilidade de pensar a vida humana no que diz respeito à capacidade da experiência perceptiva. A percepção incorpora, além dos sentidos, as características psicológicas e culturais. A experiência estética não é pura, jamais é simples sensação; ela não é apenas mediada pela cultura, mas é inerentemente cultural (BERLEANT, 2010, p. 45). O campo da experiência estética não abandona a dimensão artística, mas expande-se pelas atividades culturais e ambientais na vida cotidiana. Em suma, a experiência estética na vida cotidiana ultrapassa os limites das diatribes do campo artístico e refere-se a tanto aquilo que é positivo quanto o que é negativo na percepção cotidiana. Toda percepção possui uma dimensão estética, invisível ou não apreendida, por vezes, notável e dominante. Desta feita, a percepção estética carrega implicações na crítica e compreensão dos julgamentos no processo social (p. 51).

Nessas reflexões sobre a experiência estética que conduzem ao conceito de engajamento, a discussão sobre a imagem da paisagem nas pinturas das cidades históricas e turísticas remete a outra chave de interpretação. As ambiguidades entre sujeito e objeto, interior e exterior, observador e paisagem, em última instância revelam uma totalidade da experiência. O sujeito se objetiva enquanto o objeto é subjetivado, $o$ interior se exterioriza enquanto o exterior é interiorizado, o observador se manifesta na paisagem enquanto a paisagem invade o observador. Não há limites precisos entre esses polos da experiência. "A apreciação da natureza é uma experiência holística para a qual contribuem múltiplos fatores." (BERLEANT, 2012, p. $53)$, 


\section{Considerações finais}

Situando este artigo na interface entre a psicologia da experiência estética e os estudos do turismo, seguimos dois objetivos principais. O primeiro, colocado desde o início, chamou a atenção para o valor das pinturas nas cidades históricas e turísticas enquanto objetos da experiência estética. O segundo procurou discernir o conceito fenomenológico de engajamento para evidenciar que tais imagens participam da constituição da paisagem.

As ambiguidades daquelas narrativas encontram respaldo no trabalho do pintor, sobretudo ao reencontrarmos as palavras de Merleau-Ponty (1964, p. 16): "emprestando seu corpo ao mundo o pintor transforma o mundo em pintura". A relação estabelecida entre o corpo e o mundo circunscreve o problema da mimesis no seguinte sentido: diz respeito ao objeto icônico (a pintura) e à imagem mental, através do mundo em comum. Ambos colaboram para o exercício de conversão do mundo percebido em imagem pictórica e a produção da paisagem por meio da ação do pintor.

Quando Márcio Franco enfatiza a presença de um ponto colorido sobre um fundo verde, a imagem da paisagem começa a organizar sua forma a partir do jogo das cores. Nos artistas, André Meurer e José Andreas, os olhos percorrem a natureza e o casario, cotejando os elementos em cores, luzes e sombras. Veja-se a narrativa de Ricardo Inke na qual a luminosidade parece não pertencer ao mundo das coisas, pois move-se entre o olho, as coisas e a tela pintada na experiência unificada do pintor. Marília Inke e Júlio Paraty apontam duas perspectivas sobre o belo.

No jogo de projeções do eu sobre o mundo em comum, a expressão ou a impressão, conforme cada estilo, o que se observa é o surgimento da própria paisagem. Ela surge no movimento daqueles que percebem o mundo como imagem de arte, como partes integrantes do fenômeno da paisagem. Nessa medida, a proposição de Berleant ganha mais concretude. No contexto da experiência ambiental, a arte participa do conhecimento da paisagem (BERLEANT, 2012).

Todas as formas de arte fornecem perspectivas sobre o conhecimento da paisagem. A pintura paisagística, há mais de dois séculos, possibilita recuperar essa experiência. Não obstante, o conceito de engajamento nos auxilia a evitar o equívoco de considerar a paisagem apenas um objeto visual. Berleant traduz essa questão distinguindo duas expressões: looking at e looking within. A primeira apoia-se em apenas um aspecto da experiência (o visual), enquanto a segunda insere todo o corpo do observador no movimento vivo e dinâmico da paisagem, em todas as direções e possibilidades sensíveis, como se nadássemos na paisagem (BERLEANT, 2012, p. 56). A paisagem resulta de um processo estético, cultural e histórico, entre o artista e o espectador, por meio da pintura: "um campo estético do qual os dois fatores centrais são um evento artístico e uma localização específica” (p. 57). Todos são partes de uma única experiência.

As narrativas dos pintores de Paraty possibilitam avançar em questões tradicionais do campo artístico, sobre as correspondências entre arte e natureza, imitação e mimesis. Mas, sobretudo, colaboram para o conhecimento da paisagem das cidades históricas e turísticas em suas múltiplas perspectivas. As palavras indicam as cores, as texturas, as formas, os volumes e os movimentos que constituem a paisagem desde sua origem na experiência dos sentidos. 


\section{Agradecimentos}

Agradeço a Arnold Berleant as preciosas referências e à Fundação de Amparo à Pesquisa do Estado de São Paulo (Fapesp) o financiamento à pesquisa.

\section{Referências}

ADLER, J. Origins of sightseeing. Annals of Tourism Research, v. 16, p. 7-29, 1989.

AMIROU, R. Imaginaire touristique et sociabilité du voyage. Paris: Presses Universitaires de France, 1995.

ANDRIOLO, A. Actividad pictórica y imagen percibida: la ciudad histórico-turística de Ouro Preto. Estudios y Perspectivas en Turismo. Buenos Aires, v. 17, n. 1-2, p. 170-184, enero-abril 2008.

. A percepção da "arte barroca": psicologia social e recepção estética. In: AJZENBERG, E.; MUNANGA, K. (Org.). Arte, Cidade e Meio Ambiente. São Paulo: MAU-USP/Programa de Pós-Graduação Interunidades em Estética e História da Arte, p. 76-86, 2010.

. Metamorfoses do olhar na viagem de Goethe à Itália. ArtCultura, Uberlândia, UFU, v. 13, n. 23, Uberlândia, p. 114-127, jul.-dez. 2011.

. A pintura em Paraty: historicidade das categorias da experiência estética. In: RIBEIRO, S. P.; ARAÚJO, A. F. Paisagem, Imaginário e Narratividade: olhares transdisciplinares e novas interrogações da Psicologia Social. São Paulo: Ed. Zagodoni, p. 115-135, 2015.

BARATA, M. Djanira: época, vida e obra. Rio de Janeiro: Museu Nacional de Belas Artes, 1985.

BERLEANT, A. The aesthetics of environment. Philadelphia: Temple University Press, 1992.

. The aesthetics of art and nature. In: KELMAN, S.; GASKELL, I. (Ed.). Landscape, natural beauty and the arts. Cambridge: Cambridge University Press, p. 229-243, 1995.

The aesthetic field: a phenomenology of aesthetic experience. Christchurch, New Zealand: Cybereditions Corporation, 2000. (edição original 1970).

Sensibility and sense: the aesthetic transformation of the human world. Exeter (UK)/ Charlottesville (US): Imprint Academic, 2010.

The art in knowing a landscape. Diogenes, 59 (1-2), p. 52-62, 2012.

BOCKEMUEHL, J.; SOMBART, N. (Ed.). Awakening to landscape. Zurich/Freiburg: Freiburg Graphische Betriebe, 1992.

BOYER, M. Comment étudier le tourisme. Ethnologie Française, Paris, PUF, tomo XXXII, p. 393-404, juil.-sept. 2002-3.

COHEN, E. Introduction: investigating tourist arts. Annals of Tourism Research, v. 20, p. 1-8, 1993.

COSGROVE, D.; DANIELS, S. (Ed.). The Iconography of landscape: essays on the symbolic representation, design, and use of past environments. Cambridge: Cambridge University Press, 2000.

DUFRENNE, M. Estética e filosofia. 3. ed. São Paulo: Perspectiva, 2004. (edição original 1967). 
DURAND, J. C. Arte, privilégio e distinção: artes plásticas, arquitetura e classe dirigente no Brasil, 1855/1985. São Paulo: Perspectiva, 1989.

FESTIVAL DOS ARTISTAS DE PARATY. Garcia, L. A.; R. Inke (Org.). Catálogo de Exposição, 26 de maio a 4 de junho de 2006.

FREYRE, G. Guia prático, histórico e sentimental da cidade do Recife. Ils. Luís Jardim. 4 ed. Rio de Janeiro: Livraria Editora José Olympio, 1968. (edição original de 1934).

GEIGER, M. Problemática da estética e a estética fenomenológica. Tradução: N. Araújo. Salvador: Livraria Progresso, 1958.

GOETHE, J. W. Viagem à Itália. Tradução: S. Tellaroli. São Paulo: Cia. das Letras, 1999.

GRABURN, N. The evolution of tourist art. Annals of Tourism Research, 11(3), p. 393-419, 1994.

LAJARTE, I. Anciens villages, nouveaux peintres: de Barbizon à Pont-Aven. Paris: l'Harmattan, 1995.

LANGDRIDGE, D. Phenomenology and critical social psychology: directions and debates in theory and research. Social and Personality Psychology Compass, 2/3, p. 1126-1142, 2008.

MANNEL, R.; ISO-AHOLA, S. Psychological nature of leisure and tourism experience. Annals of Tourism Research, v. 14, p. 314-331, 1987.

MENESES, U. B. A paisagem como fato cultural. In: YÁZIGI, E. (Org.). Turismo e paisagem. São Paulo: Contexto, p. 29-64, 2002.

MERLEAU-PONTY, M. L'oeil et l'esprit. Paris: Gallimard, 1964.

MORAIS, F. Gêneros da pintura. São Paulo: Instituto Cultural Itaú, 1995.

PEARCE, P. L.; STRIGER, P. F. Psychology and tourism. Annals of Tourism Research, v. 18, p. 136-154, 1991.

PEARCE, P. Tourist behavior: themes and conceptual schemes. Toronto: Univ. of Toronto, 2005.

PIRES, M. J. Lazer e turismo cultural. Barueri: Manole, 2001.

POTTER, R.; COSHALL, J. Sociopsychological methods for tourism research. Annals of Tourism Research, v. 15, p. 63-75, 1988.

RAUCH, A. Le tourisme ou la construction de l'étrangeté. Ethnologie Française, Paris, PUF, tomo XXXII, juil.-sept., p. 389-392, 2002-3.

RIBEIRO, M. A. A paisagem mineira contemporânea. In: SALGUEIRO, H. A. (Org.). Paisagem e arte: a invenção da natureza, a evolução do olhar. São Paulo: CBHA / CNPq / Fapesp, p. 299-305, 2000.

ROGER, A. La naissance du paisage en Occident. In: SALGUEIRO, H. A. (Org.). Paisagem e arte: a invenção da natureza, a evolução do olhar. São Paulo: CBHA / CNPq / Fapesp, p. 33-39, 2010.

ROSS, G. F. Psicologia do turismo. São Paulo: Contexto, 2001.

SCHAMA, S. Paisagem e memória. São Paulo: Companhia das Letras, 1996.

SCHUTZ, A.; LUCKMANN, T. The structures of the life-world. London: Heinemann Ed. Books, 1974.

TILLEY, C. A phenomenology of landscape. Places, paths and monuments. Oxford: Berg, 1994. 